\title{
Metastatic potential of an aneurysmal bone cyst
}

\author{
Addy C. M. van de Luijtgaarden • Rene P. H. Veth • Piet J. Slootweg • \\ Pauline M. Wijers-Koster • Leo J. Schultze Kool • Judith V. M. G. Bovee • \\ Winette T. A. van der Graaf
}

Received: 29 July 2009 /Revised: 14 September 2009 /Accepted: 3 October 2009 /Published online: 17 October 2009

(C) The Author(s) 2009. This article is published with open access at Springerlink.com

\begin{abstract}
Aneurysmal bone cysts (ABCs) are benign bone tumors consisting of blood-filled cavities lined by connective tissue septa. Recently, the hypothesis that $\mathrm{ABCs}$ are lesions reactive to local hemodynamics has been challenged after the discovery of specific recurrent chromosomal abnormalities. Multiple cases of malignant transformation of $\mathrm{ABC}$ into (osteo)sarcoma have been described, as well as a number of cases of telangiectatic osteosarcoma which had been misdiagnosed as $\mathrm{ABC}$. We herewith document a case of a pelvic $\mathrm{ABC}$ metastatic to the lung, liver, and kidneys. Diagnosis was confirmed by the presence of a break in the USP6 gene, which is pathognomonic for $\mathrm{ABC}$, in a pulmonary metastasis of our patient. Sarcomatous transformation as an explanation for this behavior was ruled out by demonstrating diploid DNA content in both the pulmonary lesion and the primary tumor.
\end{abstract}

A. C. M. van de Luijtgaarden $(\bowtie) \cdot$ W. T. A. van der Graaf Department of Medical Oncology (452),

Radboud University Nijmegen Medical Centre,

P.O. Box 9101, 6500 HB Nijmegen, The Netherlands

e-mail: a.luijtgaarden@onco.umcn.nl

\section{R. P. H. Veth}

Department of Orthopedic Surgery,

Radboud University Nijmegen Medical Centre,

Nijmegen, The Netherlands

\section{P. J. Slootweg}

Department of Pathology,

Radboud University Nijmegen Medical Centre,

Nijmegen, The Netherlands

P. M. Wijers-Koster ·. V. M. G. Bovee

Department of Pathology, Leiden University Medical Centre, Leiden, The Netherlands

\section{J. Schultze Kool}

Department of Interventional Radiology,

Radboud University Nijmegen Medical Centre,

Nijmegen, The Netherlands
Keywords Bone cysts · Aneurysmal · Neoplasm metastasis · Image cytometry

\section{Introduction}

Primary aneurysmal bone cysts $(\mathrm{ABC})$ account for $1-2 \%$ of all primary bone tumors and are usually present in the first two decades of life [1]. They are composed of blood-filled spaces separated by connective tissue septa that contain fibroblasts, osteoclast-type giant cells, and reactive woven bone [2]. The pathogenesis of primary $\mathrm{ABC}$ is still incompletely understood. In the past, $\mathrm{ABCs}$ were considered reactive lesions caused by altered local hemodynamics. More recently, it was shown that primary ABCs contain recurrent chromosomal abnormalities [3-13]. This suggests that primary $\mathrm{ABCs}$ are true neoplasms [1]. The differential diagnosis of primary $\mathrm{ABC}$ includes other giant cellcontaining tumors of the bone, particularly giant cell tumor (GCT) [14]. ABC-like areas can also be seen in association with other tumors such as chondroblastoma (secondary $\mathrm{ABC}$ ). Furthermore, cases of sarcomatous transformation of $\mathrm{ABCs}$, often occurring after exposure to ionizing radiation, and of misdiagnosed telangiectatic osteosarcoma have been recognized. However, even without sarcomatous transformation, $\mathrm{ABC}$ may metastasize as is described in this report.

\section{Clinical history}

A 48-year-old woman was referred to our hospital for treatment of a giant $\mathrm{ABC}$ of the left ilium, measuring 27.6× $22.4 \times 15.9 \mathrm{~cm}$ (Fig. 1). Her medical history comprised of a hysterectomy for uterine cervical carcinoma in 1995, strumectomy for adenomatous thyroid hyperplasia in 1998, 


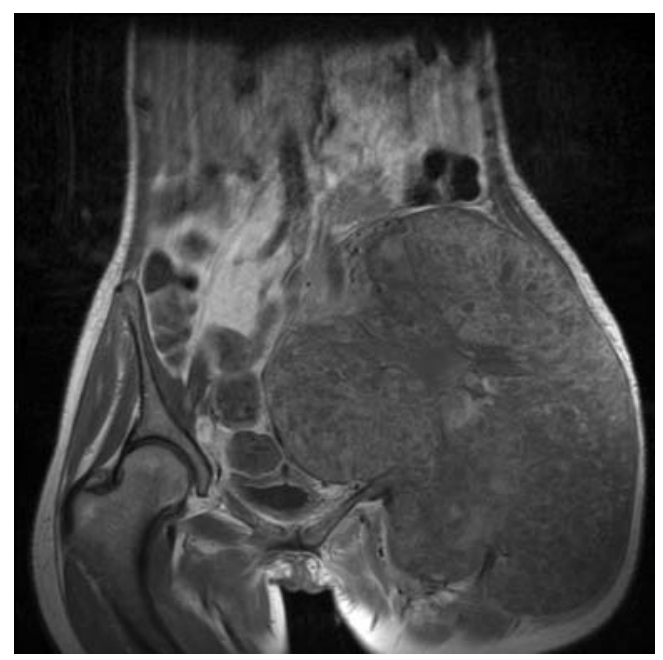

Fig. 1 Magnetic resonance image of the pelvis on admission showing a large $\mathrm{ABC}$ of the left ilium

and type II diabetes mellitus since 2004. For the ABC, she had been treated elsewhere with embolization (coiling and alcoholic zein injection; Ethibloc, Ethicon, Johnson \& Johnson, New Brunswick, NJ, USA) and repeated surgery, all over a 1-year period. Wide local excision had not been achieved due to massive hemorrhage during surgical interventions. In our hospital, preoperative embolization and percutaneous intralesional alcohol injection were performed and staged resection of the alcohol-treated areas combined with cryosurgery was attempted. Furthermore, offlabel systemic treatment with the monoclonal antivascular endothelial growth factor (VEGF) antibody bevacizumab (Avastin; Roche, Basel, Switzerland; Genentech, South San Francisco, California, USA) $10 \mathrm{mg} / \mathrm{kg}$ administered intravenously every other week was applied to reduce bleeding tendency. The latter was based on the reports by Kumta et al. and Shinde et al. showing VEGF positivity in $100 \%$ and $50 \%$ of primary $\mathrm{ABCs}$, respectively $[15,16]$. In our patient, plasma and cyst fluid VEGF levels were determined by enzyme-linked immunosorbent assay and found to be elevated (1.12 and $16.5 \mathrm{ng} / \mathrm{ml}$, respectively; in-house control series of 23 healthy women: plasma average $=0.166 \mathrm{ng} / \mathrm{ml}$, range $=0.028-0.966 \mathrm{ng} / \mathrm{ml})$.

This strategy facilitated near-complete resection of the $\mathrm{ABC}$ by limiting intraoperative blood loss. However, clinical heart failure developed in our patient, prompting the discontinuation of bevacizumab. This was followed by a rapid regrowth of the pelvic lesion. After a total of seven surgical sessions, the patient's condition no longer allowed surgical interventions and it was decided to apply radiotherapy at a total dose of 39 Gy. Unexpectedly, at this time, radiographical treatment evaluation showed previously undiscovered lesions in both lungs and in the left kidney. Widespread metastatic behavior of this until then judged benign bone neoplasm was suspected, while differential diagnosis included secondary $\mathrm{ABC}$ in a yet unidentified primary bone malignancy, malignant transformation of $\mathrm{ABC}$, misdiagnosed $\mathrm{GCT}$, or telangiectatic osteosarcoma. The patient's condition no longer allowed any treatment and she died 2 years after $\mathrm{ABC}$ was first diagnosed. At autopsy, metastases were found in both lungs, both kidneys, and the liver.

\section{Materials and methods}

\section{Pathology}

Formalin-fixed paraffin-embedded specimens were available from all resections of the primary tumor. Sections from all samples were stained by the hematoxylin and
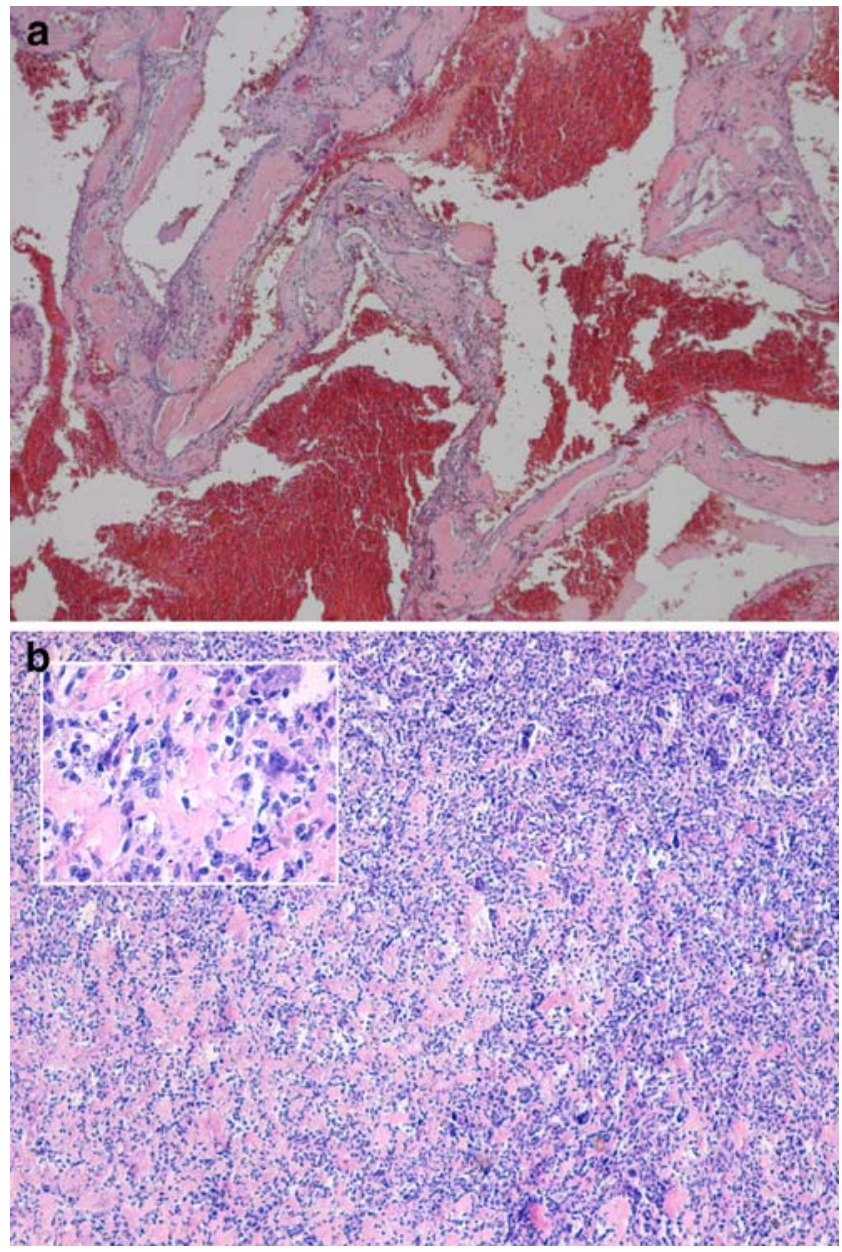

Fig. 2 a Photomicrograph of material from the first excision (hematoxylin and eosin, $\times 50$ ) showing a blood-filled cavity and solid component containing strands of woven bone with interspersed fibroblasts. b Photomicrograph of the lung lesion removed at autopsy. A low-powered (hematoxylin and eosin, $\times 50$ ) and high-powered (inset, hematoxylin and eosin, $\times 200$ ) view show that no blood-filled cystic cavities were found at this site; the lesion only resembled the solid parts of the pelvic location 
eosin method and re-examined for evidence of malignancy by multiple expert pathologists (PS, JB, and independent multidisciplinary revision by the Netherlands Committee on Bone Tumors).

\section{Image cytometry}

Three samples (two were obtained from the primary tumor at referral to our hospital and during the last resection, respectively, and the third was a pulmonary metastasis obtained during autopsy) were selected for DNA quantification by image cytometry. At least two 50 - $\mu \mathrm{m}$-thick sections were obtained of each sample followed by a 4- $\mu \mathrm{m}$ hematoxylin and eosin section to check for representativeness. An adaptation of the method described by Hedley [17] was used for cell nuclei extraction from the sections. The obtained suspensions were filtered with a Partec 50- $\mu \mathrm{m}$ CellTrics filter (Partec, Münster, Germany) and prepared into a monolayer by cytospin. Nuclei were stained with Feulgen's stain and periodic acid Schiff. The samples were evaluated using a cytometric image analysis system (QPATH, Leica Imaging Systems, Cambridge, UK) that consists of an automated microscope with a digital camera connected to a computer that runs DNA analysis software. Of each specimen, 5,000 nuclei were scanned and a minimum of 2,000 images of tumor cell nuclei were manually selected avoiding debris, necrotic or cut cells, and cell clusters. Lymphocytes were used as the standard internal controls. Histogram quality was evaluated by integrated optical density (IOD) values and its coefficient of variation (CV); $15 \leq \mathrm{IOD} \leq 25$ and $\mathrm{CV} \leq 5 \%$ were considered acceptable. Criteria for ploidy classification were taken from the guidelines of the European Society for Analytical Cellular Pathology [18].
Fluorescence in situ hybridization

Fluorescence in situ hybridization (FISH) was performed on the lung metastasis using BAC probes flanking the USP6 gene, largely as described [19].

\section{Results}

Histological examination of material obtained from the primary tumor in the pelvis during the first surgical procedure showed a multicystic lesion with blood-filled spaces (Fig. 2a). The septa consisted of fibroblasts which showed no cytological features of malignancy such as nuclear atypia or an increased number of mitoses. Interspersed were woven bone fragments. No evidence of an underlying primary lesion causing secondary $\mathrm{ABC}$, neither of evident malignant transformation of $\mathrm{ABC}, \mathrm{GCT}$, nor telangiectatic osteosarcoma was found. The morphology of the primary lesion was thus consistent with a primary $\mathrm{ABC}$. The other excision specimens subsequently obtained from this pelvic tumor showed similar histology. The lung lesion resembled the solid parts of the pelvic location; no bloodfilled cystic spaces were found here (Fig. 2b). Again, no cytological features of malignancy were found. The three samples (two obtained from the primary tumor and one pulmonary lesion) that were evaluated for DNA content were diploid. FISH performed on the pulmonary lesion showed a break in the USP6 gene in up to $43 \%$ of the nuclei: $24 \%$ of the nuclei showed segregation of the signal in addition to two normal (colocalization) chromosomes 17 (Fig. 3, left panel), 15\% of the nuclei showed two normal chromosomes 17 and a single red signal (Fig. 3, middle panel), 4\% showed one colocalization and one segregation of the signal (Fig. 3, right panel).

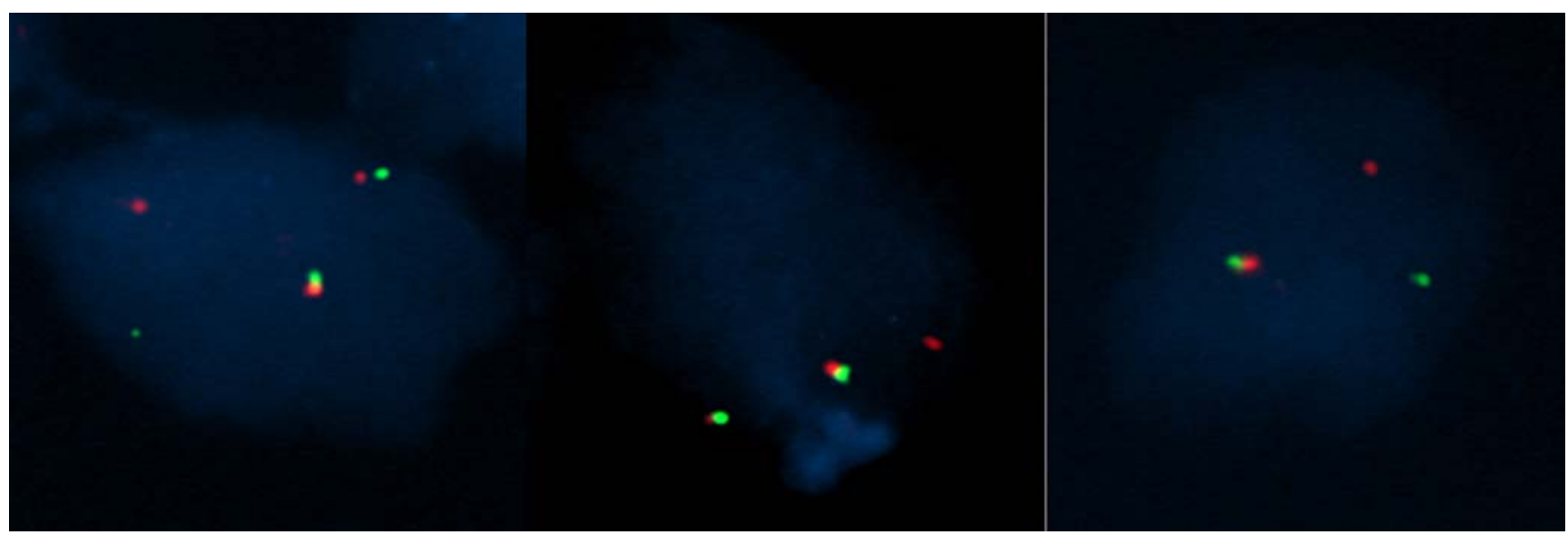

Fig. 3 FISH images of the lung lesion removed at autopsy using BAC probes flanking the USP6 gene showing segregation of the signal and colocalization of two normal chromosomes 17 (left panel), two normal chromosomes 17 and a single red signal (middle panel), and one colocalization and one segregation of the signal (right panel) 


\section{Discussion}

Since the discovery of recurrent chromosomal abnormalities, of which $t(16 ; 17)(q 22 ; p 13)$ is the most frequent [3$13]$, primary $\mathrm{ABC}$ is no longer considered a reactive lesion but rather a true benign neoplasm [1]. The $t(16 ; 17)$ translocation was later shown to relocate the promoter of CDH11, a gene that is strongly expressed in bone, in front of the USP6 gene (TRE2, TRE17) [8]. Over the past few years, a series of different translocations has been described in $\mathrm{ABC}[8,13]$, all resulting in oncogenic activation of the USP6 gene on chromosome 17p13. Thus, the pathogenesis of most primary ABCs involves upregulation of USP6 transcription driven by other highly active promoters [20]. The mechanism by which USP6 upregulation causes ABC formation has not yet been elucidated. USP6 rearrangements were shown to be restricted to the spindle cells and were absent in the multinucleated giant cells, inflammatory cells, endothelial cells, and osteoblasts [8]. This suggests that the neoplastic spindle cells induce a vigorous, reactive host response mimicking young granulation tissue, explaining why for a long time the lesions were regarded reactive [8]. The majority of $\mathrm{ABC}$ patients are treated by local curettage combined with intraoperative adjuvant therapy (e.g., cryosurgery or phenol application) with local control rates as high as $70-90 \%$. Almost all cases of recurrence can be treated by re-resection [1].

To our knowledge, there are no previous reports of metastatic behavior of primary ABC. Therefore, we considered the possibility of secondary $\mathrm{ABC}$ in a yet unidentified primary bone malignancy, malignant transformation of $\mathrm{ABC}$, misdiagnosed GCT, or telangiectatic osteosarcoma. ABC-like areas can be seen in association with GCT, occasionally overgrowing the underlying primary tumor, and $\mathrm{ABC}$ can contain solid areas strongly resembling GCT [21]. In contrast with $\mathrm{ABC}$, GCT may metastasize in $2-3 \%$ of cases, particularly to the lungs. The diploid DNA content we found cannot exclude GCT with metastatic potential [22, 23]. However, while chromosome 16 and 17 abnormalities have been found infrequently in GCT [24-26], the $\mathrm{t}(16 ; 17)(\mathrm{q} 22$; p13) translocation $[8,27]$ and USP6 upregulation [8] are absent in reported cases. We also tested three GCTs and could not detect a USP6 rearrangement (data not shown). Thus, it seems highly unlikely that our case represented metastasizing GCT of bone. Moreover, the USP6 rearrangement was demonstrated in the lung metastasis, indicating that, even if from the beginning it had been $\mathrm{ABC}$ secondary to and totally overgrowing an underlying primary bone lesion such as GCT, it is the ABC part that metastasized. Moreover, USP6 rearrangements have not been found in secondary $\mathrm{ABC}$ so far [19].

Telangiectatic osteosarcoma and $\mathrm{ABC}$ can be radiologically identical and histologically very difficult to distin- guish [28-30]. Nuclear atypia and an increased number of mitoses favor telangiectatic osteosarcoma. As an additional diagnostic tool, several reports have suggested the use of DNA cytometry to distinguish these entities. Whereas $\mathrm{ABCs}$ are known for diploid DNA content, telangiectatic osteosarcomas show complex karyotypes and numerous gains and losses [31-33]. Moreover, in ABC, CDH11USP6 fusions as well as USP6 upregulation are pathognomonic, while they are absent in osteosarcoma $[8,9]$. So, the diploid nature of the lesion in our case, both in primary as well as metastatic deposits, adequately rules out telangiectatic osteosarcoma as an alternative diagnosis.

In summary, in our patient, all histological samples obtained over a 2-year period were consistent with $\mathrm{ABC}$ while lacking cytological features of malignancy. Absence of malignant transformation was supported by DNA content analysis: three selected samples including a pulmonary metastasis all had diploid DNA content. Finally, we found a rearrangement of the USP6 gene by FISH in $43 \%$ of nuclei in the pulmonary lesion, which is within the highly variable range of positive cells (7-82\%) reported for $\mathrm{ABC}$ [19].We ruled out sarcomatous transformation or GCT as cause of the metastatic behavior and confirmed the diagnosis of $\mathrm{ABC}$ by our FISH data.

It can be hypothesized that the numerous surgical and interventional radiological manipulations that were necessary in our patient have facilitated the hematogenous spread of $\mathrm{ABC}$ cell clusters. Furthermore, though bevacizumab proved successful in reducing bleeding tendency, recent reports about antiangiogenic therapy-induced malignant progression of tumors to increased invasion and accelerated metastasis raise concern about a similar effect in our patient.

Acknowledgements We thank Dr. K. Szuhai for the help with the FISH analysis and the Netherlands Committee on Bone Tumors for their critical reappraisal of all histological samples obtained from this patient.

Conflict of interest statement The authors declare that they have no conflict of interest.

Open Access This article is distributed under the terms of the Creative Commons Attribution Noncommercial License which permits any noncommercial use, distribution, and reproduction in any medium, provided the original author(s) and source are credited.

\section{References}

1. Mendenhall WM, Zlotecki RA, Gibbs CP et al (2006) Aneurysmal bone cyst. Am J Clin Oncol 29(3):311-315

2. Rosenberg AE, Nielsen GP, Fletcher JA (2002) Aneurysmal bone cyst. In: Fletcher CDM, Unni KK, Mertens F (eds) World Health Organization classification of tumours: pathology and genetics of tumours of soft tissue and bone. International Agency for Research on Cancer, Lyon, pp 338-339

3. Althof PA, Ohmori K, Zhou M et al (2004) Cytogenetic and molecular cytogenetic findings in 43 aneurysmal bone cysts: 
aberrations of $17 \mathrm{p}$ mapped to $17 \mathrm{p} 13.2$ by fluorescence in situ hybridization. Mod Pathol 17(5):518-525

4. Baruffi MR, Neto JB, Barbieri CH et al (2001) Aneurysmal bone cyst with chromosomal changes involving $7 \mathrm{q}$ and $16 \mathrm{p}$. Cancer Genet Cytogenet 129(2):177-180

5. Dal CP, Kozakewich HP, Goumnerova L et al (2000) Variant translocations involving $16 \mathrm{q} 22$ and $17 \mathrm{p} 13$ in solid variant and extraosseous forms of aneurysmal bone cyst. Genes Chromosomes Cancer 28(2):233-234

6. Ellison DA, Sawyer JR, Parham DM et al (2007) Soft-tissue aneurysmal bone cyst: report of a case with $\mathrm{t}(5 ; 17)(\mathrm{q} 33 ; \mathrm{p} 13)$. Pediatr Dev Pathol 10(1):46-49

7. Kenney B, Richkind KE, Zambrano E (2007) Solid variant of aneurysmal bone cyst with a novel $(X ; 9)$ translocation. Cancer Genet Cytogenet 178(2):155-159

8. Oliveira AM, Hsi BL, Weremowicz S et al (2004) USP6 (Tre2) fusion oncogenes in aneurysmal bone cyst. Cancer Res 64 (6): $1920-1923$

9. Panoutsakopoulos G, Pandis N, Kyriazoglou I et al (1999) Recurrent $\mathrm{t}(16 ; 17)(\mathrm{q} 22 ; \mathrm{p} 13)$ in aneurysmal bone cysts. Genes Chromosomes Cancer 26(3):265-266

10. Sciot R, Dorfman H, Brys P et al (2000) Cytogenetic-morphologic correlations in aneurysmal bone cyst, giant cell tumor of bone and combined lesions. A report from the CHAMP study group. Mod Pathol 13(11):1206-1210

11. Winnepenninckx V, biec-Rychter M, Jorissen M et al (2001) Aneurysmal bone cyst of the nose with $17 \mathrm{p} 13$ involvement. Virchows Arch 439(5):636-639

12. Wyatt-Ashmead J, Bao L, Eilert RE et al (2001) Primary aneurysmal bone cysts: $16 \mathrm{q} 22$ and/or $17 \mathrm{p} 13$ chromosome abnormalities. Pediatr Dev Pathol 4(4):418-419

13. Oliveira AM, Perez-Atayde AR, Dal CP et al (2005) Aneurysmal bone cyst variant translocations upregulate USP6 transcription by promoter swapping with the ZNF9, COL1A1, TRAP150, and OMD genes. Oncogene 24(21):3419-3426

14. Rosenberg AE, Nielsen GP (2001) Giant cell containing lesions of bone and their differential diagnosis. Curr Diagn Pathol 7(4):235-246

15. Kumta SM, Huang L, Cheng YY et al (2003) Expression of VEGF and MMP-9 in giant cell tumor of bone and other osteolytic lesions. Life Sci 73(11):1427-1436

16. Shinde A, Mehlman CT, Collins MH (2006) Aneurysmal bone cysts express vascular markers. Pediatr Dev Pathol 9(1):38-43

17. Hung IJ, Yang CP, Jaing TH (2003) Patterns of cancer distribution in a medical center among adolescents 14 to 17 years of age for the period 1995 to 2001. J Formos Med Assoc 102(9):631-636

18. Haroske G, Baak JP, Danielsen H et al (2001) Fourth updated ESACP consensus report on diagnostic DNA image cytometry. Anal Cell Pathol 23(2):89-95
19. Oliveira AM, Perez-Atayde AR, Inwards CY et al (2004) USP6 and $\mathrm{CDH} 11$ oncogenes identify the neoplastic cell in primary aneurysmal bone cysts and are absent in so-called secondary aneurysmal bone cysts. Am J Pathol 165(5):1773-1780

20. Oliveira AM, Chou MM, Perez-Atayde AR et al (2006) Aneurysmal bone cyst: a neoplasm driven by upregulation of the USP6 oncogene. J Clin Oncol 24(1):e1

21. Vergel De Dios AM, Bond JR, Shives TC et al (1992) Aneurysmal bone cyst. A clinicopathologic study of 238 cases. Cancer 69(12):2921-2931

22. Osaka S, Toriyama M, Taira K et al (1997) Analysis of giant cell tumor of bone with pulmonary metastases. Clin Orthop Relat Res 335:253-261

23. Takanami I, Imamura $\mathrm{T}$, Morota $\mathrm{N}$ et al (1994) Recurrent pulmonary metastases from benign giant cell tumors of the bone: report of two cases and analysis of nuclear DNA content by flow cytometry. Surg Today 24(5):476-480

24. Bridge JA, Neff JR, Mouron BJ (1992) Giant cell tumor of bone. Chromosomal analysis of 48 specimens and review of the literature. Cancer Genet Cytogenet 58(1):2-13

25. Molenaar WM, van den Berg E, Dolfin AC et al (1995) Cytogenetics of fine needle aspiration biopsies of sarcomas. Cancer Genet Cytogenet 84(1):27-31

26. Gorunova L, von Vult SF, Storlazzi CT et al (2009) Cytogenetic analysis of 101 giant cell tumors of bone: nonrandom patterns of telomeric associations and other structural aberrations. Genes Chromosomes Cancer 48(7):583-602

27. Mitelman F, Johansson B, Mertens F (eds) (2008) Mitelman database of chromosome aberrations in cancer. Ref type: Data file. Available at http://cgap.nci.nih.gov/Chromosomes/Mitelman

28. Gomes H, Menanteau B, Gaillard D et al (1986) Telangiectatic osteosarcoma. Pediatr Radiol 16(2):140-143

29. Vanel D, Tcheng S, Contesso $G$ et al (1987) The radiological appearances of telangiectatic osteosarcoma. A study of 14 cases. Skeletal Radiol 16(3):196-200

30. Vigliani F, Campailla E (1987) Mimickry in osteogenic sarcoma. Clinical considerations and report of 2 cases. Ital J Orthop Traumatol 13(4):425-436

31. el-Naggar AK, Hurr K, Tu ZN et al (1995) DNA and RNA content analysis by flow cytometry in the pathobiologic assessment of bone tumors. Cytometry 19(3):256-262

32. Werner M, Heintz A, Delling G (1996) DNA cytometry of solitary and aneurysmal bone cysts and low malignancy and high malignancy central osteosarcomas. Current significance within the scope of morphologic diagnosis of intraosseous cystic and osteoblastic lesions. Pathologe 17(1):44-49

33. Bauer HC, Kreicbergs A, Silfversward C et al (1988) DNA analysis in the differential diagnosis of osteosarcoma. Cancer 61(12):25322540 